\title{
Characterization of Sideritis trojana Bornm. essential oil and its antimicrobial activity
}

\author{
Hasan KIRMIZIBEKMEZ, Nursenem KARACA, Betül DEMİRCİ, Fatih DEMİRCİ
}

\begin{abstract}
The components of the essential oil obtained from the dried aerial parts of Sideritis trojana Bornm. by hydrodistillation was analyzed both by GC-FID and GC-MS, simultaneously. Overall 57 compounds were identified representing $83.8 \%$ of the oil. The major components of the oil were identified as valeranone (11.3\%), $\alpha$-bisabolol (10.9\%) and $\beta$-caryophyllene (8.8\%), respectively. The composition of the oil showed quantitative chemical variation from previously studied material in terms of its major components. Moreover, the essential oil was evaluated for its in vitro antibacterial and anticandidal activities using
\end{abstract}

a broth microdilution method. A selected panel of standard strains of Gram (+) and Gram (-) human pathogens as well as Candida albicans were used in the assay. As a preliminary result, it was observed that the oil displayed relatively moderate antibacterial activity against Helicobacter pylori with MIC value of $250 \mu \mathrm{g} / \mathrm{mL}$ when compared to standard antimicrobials. As a conclusion, it is worthwhile to evaluate the plant material against a broader spectrum of activities.

Key words: Sideritis trojana; Lamiaceae; essential oil; GC-FID and GC-MS; antimicrobial; Helicobacter pylori.
Hasan Kirmizibekmez

Department of Pharmacognosy, Faculty of Pharmacy, Yeditepe University, TR34755, Kayışdağı, İstanbul, Turkey

Nursenem Karaca, Betül Demirci

Department of Pharmacognosy, Graduate School of Health Sciences, Anadolu University, TR-26470 Eskişehir, Turkey

Betül Demirci, Fatih Demirci

Department of Pharmacognosy, Faculty of Pharmacy, Anadolu University, TR-26470 Eskişehir, Turkey

Fatih Demirci

Faculty of Health Sciences, Anadolu University, TR-26470 Eskişehir, Turkey

Corresponding Author:

Hasan Kırmızıbekmez

e-mail:hasankbekmez@yahoo.com

Submitted / Gönderilme: 24.05 .2017

Accepted / Kabul: $\quad 28.06 .2017$

How to cite this article: Kırmızıbekmez H, Karaca N, Demirci B, Demirci F. Characterization of Sideritis trojana Bornm. essential oil and its antimicrobial activity. Marmara Pharm J 2017; 21 (4): 860-865

\section{Introduction}

The genus Sideritis L. contains over 150 species distributed in the temperate and tropical regions of the world especially in the Mediterranean basin [1]. Sideritis trojana Bornm. (Lamiaceae) is known as "kazdağ its aerial parts are sold in local bazaars. It is widely used as a popular herbal tea for the treatment of stomach ache, abdominal pain, kidney disease as well as against sore throat in the Balıkesir and Çanakkale provinces of Turkey where the plant species grow wild [2]. This species is endemic to Ida Mountains and constitutes one of the $46^{\text {th }}$ Sideritis species in the flora of Turkey $[3,4]$. Previous phytochemical studies reported the occurrence of diterpenes [5], essential oil [6], iridoids, phenylethanoid glycosides and flavonoids [7] in the aerial and underground parts of this species. Moreover, the in vitro antimicrobial [8] and antioxidant activities [7] of different extracts and/or the secondary metabolites purified thereof were reported. The different solvent extracts as well as the essential oils obtained from various Sideritis species were also reported to possess antimicrobial activities $[1,6]$. In the course of our ongoing phytochemical and bioactivity studies on Lamiaceae plants, we herein report the chemical characterization of $S$. trojana essential oil distilled from the 
aerial parts as well as its in vitro antimicrobial activity against five bacteria and a Candida standard strain.

\section{Results and Discussion}

\subsection{Essential oil composition}

Analysis of the essential oil was carried out by GC-FID and GC-MS, simultaneously. Totally, 57 compounds were identified representing $83.8 \%$ of the essential oil (Table 1). The essential oil was mainly represented by oxygenated sesquiterpenes $(28.7 \%)$ and sesquiterpene hydrocarbons (19.1\%) including valeranone (11.3\%), a-bisabolol (10.9\%), $\beta$-caryophyllene (8.9\%) and germacrene $\mathrm{D}(4.4 \%)$ and caryophyllene oxide (4.2\%). The other major compounds of the oil were as follows: $\alpha$-pinene $(5.2 \%)$ and 9-geranyl- $p$ cymene (4.8\%). S. trojana belongs to the section Empedoclia (Rafin.) Bentham. which constitutes one of the two sections of Sideritis species growing in Turkey [3]. Kırımer et al. reported the chemical composition of the essential oil of two Sideritis species including S. trojana [6]. The essential was reported to be dominated by monoterpene hydrocarbons ( $\alpha / \beta$-pinenes; 31.6\%). When the overall chemical composition of the essential oil obtained in this study is compared to that of the same species reported previously [6], the major differences were quantitative rather than qualitative. In other words, the relative abundance of the volatile principles of $S$. trojana showed variation between these two studies. As the plant materials were collected from very close locations, the variations might arise due to the possible different collection periods. It is also noteworthy that 9-geranyl-p-cymene, a volatile diterpene that was found in the oil at $4.8 \%$ could be a useful chemotaxonomic marker for S. trojana within Sideritis genus. When the oil yield is compared to those of other Sideritis species, it was found rather low (0.08\%) in the current study and it also seems to be in line with the hypothesis "the lower the oil yield the higher the sesquiterpene yield" of Kirımer et al. for the essential oils of Sideritis species in the section Empedoclia [9]. The same authors also categorized Sideritis species growing in Turkey into six groups according to their major compounds of the essential oil as "monoterpene hydrocarbon rich", "oxygenated monoterpene rich", "sesquiterpene hydrocarbon rich", "oxygenated sesquiterpene rich", "diterpene rich" and "others" $[9,10]$. As inferred from Table 1, the essential oil of $S$. trojana is rich in oxygenated sesquiterpenes. It is stated that $S$. trojana is morphologically close to $S$. taurica and $S$. dichotoma [3]. When the essential oil composition of $S$. trojana is compared to those of $S$. taurica and S. dichotoma, the oil of $S$. trojana seems to be closer to that of $S$. taurica as both essential oils contain $a$-bisabolol and germacrene $\mathrm{D}$ as the major sesquiterpenes whereas $S$. dichotoma is reported to be rich in diterpenes mainly geraterpinene [9].

\subsection{Antimicrobial activity}

The isolated essential oil was evaluated for its antimicrobial activity against five bacteria strains including Helicobacter pylori ATCC 43504 strain as well as a human pathogenic Candida strain. The essential oil displayed a relative moderate activity against $H$. pylori with MIC value of $250 \mu \mathrm{g} / \mathrm{mL}$. In a previous study by Kirımer et al. the essential oil of $S$. trojana was found to possess mild to moderate antimicrobial activity against E. coli, S. epidermidis and C. albicans (MICs: 62.5$125 \mathrm{mg} / \mathrm{mL}$ ) [6]. However, in the present study the microbial panel was not susceptible to essential oil at the tested concentrations. The difference between the results might be due to the quantitative variations between these samples as discussed above as well as might arise from the different microbial strains tested.

\section{Conclusion}

The chemical composition of the essential oil isolated from the aerial parts of S. trojana was analysed by GC-FID and GC-MS. The essential oil of plant material was found to be rich in oxygenated sesquiterpenes. The essential oil exerted moderate activity against $H$. pylori with MIC value of $250 \mu \mathrm{g} /$ $\mathrm{mL}$. This is the first report on the in vitro anti-helicobacter activity of $S$. trojana essential oil. Despite its relatively low amount, the essential oil of $S$. trojana might contribute to its folkloric usage to some extent against stomach ache. In conclusion it can be suggested that this species should be evaluated in more detail for its chemistry and biological activities.

\section{Materials and Methods}

\subsection{Plant material}

Plant material, the dried aerial parts of Sideritis trojana Bornm. in flowering stage was purchased from a local bazaar in Altınoluk, Edremit, Balıkesir, Turkey, in August 2016. The plant material was identified by one of us (Dr. H. Kirmizibekmez) and a sample is deposited at the Pharmacognosy Research Laboratory, Faculty of Pharmacy, Yeditepe University. 
Table 1. Chemical composition of the essential oil of Sideritis trojana

\begin{tabular}{|c|c|c|c|c|}
\hline No & $\mathbf{R R I}^{\mathrm{a}}$ & Compound & $(\%)$ & $\begin{array}{l}\text { Identification } \\
\text { Method }^{\mathrm{d}}\end{array}$ \\
\hline 1 & 1032 & a-Pinene & $2.73 \pm 0.05^{b}$ & RRI, MS \\
\hline 2 & 1035 & a-Thujene & $0.10 \pm 0$ & MS \\
\hline 3 & 1118 & $\beta$-Pinene & $5.17 \pm 0.05$ & RRI, MS \\
\hline 4 & 1132 & Sabinene & $0.33 \pm 0.05$ & RRI, MS \\
\hline 5 & 1159 & d-3-Carene & $0.50 \pm 0$ & MS \\
\hline 6 & 1174 & Myrcene & $0.30 \pm 0$ & RRI, MS \\
\hline 7 & 1194 & Heptanal & $0.20 \pm 0$ & RRI, MS \\
\hline 8 & 1203 & Limonene & $1.60 \pm 0$ & RRI, MS \\
\hline 9 & 1218 & $\beta$-Phellandrene & $0.40 \pm 0$ & RRI, MS \\
\hline 10 & 1225 & (Z)-3-Hexenal & $0.17 \pm 0.05$ & MS \\
\hline 11 & 1244 & 2-Pentyl furan & $0.10 \pm 0$ & MS \\
\hline 12 & 1246 & $(Z)-\beta$-Ocimene & $0.50 \pm 0$ & MS \\
\hline 13 & 1255 & $\gamma$-Terpinene & $\operatorname{tr}^{c}$ & RRI, MS \\
\hline 14 & 1266 & (E)- $\beta$-Ocimene & $\operatorname{tr}$ & MS \\
\hline 15 & 1280 & p-Cymene & $1.30 \pm 0$ & RRI, MS \\
\hline 16 & 1296 & Octanal & $0.20 \pm 0$ & RRI, MS \\
\hline 17 & 1393 & 3-Octanol & $0.23 \pm 0.05$ & MS \\
\hline 18 & 1400 & Nonanal & $1.67 \pm 0.05$ & RRI, MS \\
\hline 19 & 1452 & 1-Octen-3-ol & $1.90 \pm 0.08$ & MS \\
\hline 20 & 1497 & a-Copaene & $0.27 \pm 0.05$ & RRI, MS \\
\hline 21 & 1499 & a-Campholene aldehyde & $0.10 \pm 0$ & MS \\
\hline 22 & 1541 & Benzaldehyde & $0.23 \pm 0.05$ & RRI, MS \\
\hline 23 & 1548 & (E)-2-Nonenal & $0.30 \pm 0$ & MS \\
\hline 24 & 1553 & Linalool & $0.87 \pm 0.05$ & RRI, MS \\
\hline 25 & 1562 & Octanol & $0.90 \pm 0$ & RRI, MS \\
\hline 26 & 1586 & Pinocarvone & $0.33 \pm 0.05$ & RRI, MS \\
\hline 27 & 1612 & $\beta$-Caryophyllene & $8.87 \pm 0.21$ & RRI, MS \\
\hline 28 & 1648 & Myrtenal & $0.70 \pm 0$ & MS \\
\hline 29 & 1655 & (E)-2-Decenal & $0.10 \pm 0$ & MS \\
\hline 30 & 1663 & cis-Verbenol & $0.10 \pm 0$ & MS \\
\hline 31 & 1668 & $(Z)-\beta$-Farnesene & $0.90 \pm 0$ & MS \\
\hline 32 & 1670 & trans-Pinocarveol & $0.90 \pm 0$ & RRI, MS \\
\hline 33 & 1687 & a-Humulene & $0.20 \pm 0$ & RRI, MS \\
\hline 34 & 1683 & trans-Verbenol & $0.77 \pm 0.05$ & MS \\
\hline 35 & 1706 & a-Terpineol & $0.50 \pm 0$ & RRI, MS \\
\hline 36 & 1726 & Germacrene D & $4.40 \pm 0.08$ & MS \\
\hline 37 & 1741 & $\beta$-Bisabolene & $2.27 \pm 0.05$ & MS \\
\hline 38 & 1755 & Bicyclogermacrene & $1.50 \pm 0$ & MS \\
\hline 39 & 1773 & d-Cadinene & $0.27 \pm 0.05$ & MS \\
\hline 40 & 1784 & (E)- $\alpha$-Bisabolene & $0.40 \pm 0.08$ & MS \\
\hline 41 & 1804 & Myrtenol & $0.63 \pm 0.05$ & MS \\
\hline 42 & 1864 & p-Cymen-8-ol & $0.30 \pm 0$ & RRI, MS \\
\hline 43 & 1958 & $(E)$ - $\beta$-Ionone & $0.23 \pm 0.05$ & RRI, MS \\
\hline 44 & 2001 & Isocaryophyllene oxide & $0.53 \pm 0.05$ & MS \\
\hline 45 & 2008 & Caryophyllene oxide & $4.20 \pm 0.08$ & RRI, MS \\
\hline 46 & 2041 & Pentadecanal & $0.27 \pm 0.05$ & RRI, MS \\
\hline 47 & 2071 & Humulene epoxide-II & $0.10 \pm 0$ & RRI, MS \\
\hline 48 & 2131 & Hexahydrofarnesyl acetone & $0.5 \pm 0$ & MS \\
\hline 49 & 2145 & Valeranone & $11.37 \pm 0.05$ & MS \\
\hline 50 & 2232 & a-Bisabolol & $10.97 \pm 0.19$ & RRI, MS \\
\hline
\end{tabular}




\begin{tabular}{|c|c|c|c|c|}
\hline 51 & 2247 & trans-a-Bergamotol & $0.40 \pm 0$ & MS \\
\hline 52 & 2255 & a-Cadinol & $1.10 \pm 0$ & MS \\
\hline 53 & 2312 & 9-Geranyl-p-cymene & $4.80 \pm 0.08$ & MS \\
\hline 54 & 2337 & Kaur-15-ene $\alpha$ & $0.60 \pm 0$ & MS \\
\hline 55 & 2384 & Hexadecanol & $0.27 \pm 0.09$ & MS \\
\hline 56 & 2655 & Benzyl benzoate & $2.43 \pm 0.05$ & MS \\
\hline \multirow[t]{9}{*}{57} & 2931 & Hexadecanoic acid & $2.83 \pm 0.27$ & RRI, MS \\
\hline & & Monoterpene Hydrocarbons & 12.93 & \\
\hline & & Oxygenated Monoterpenes & 5.2 & \\
\hline & & Sesquiterpene Hydrocarbons & 19.08 & \\
\hline & & Oxygenated Sesquiterpenes & 28.67 & \\
\hline & & Fatty acid+esters & 2.83 & \\
\hline & & Diterpenes & 5.4 & \\
\hline & & Others & 9.7 & \\
\hline & & Total & $83.81 \pm 0.12$ & \\
\hline
\end{tabular}

${ }^{a}$ RRI: Relative retention indices calculated against $n$-alkanes; \% calculated from FID data; ${ }^{\mathrm{b}}$ mean $\%$ calculated from Flame Ionization Detector (FID) data \pm SD $(n=3)$; ${ }^{\mathrm{c}} \operatorname{tr}$ Trace $(<0.1 \%)$; ${ }^{\mathrm{d}}$ Identification method based on the relative retention indices (RRI) of authentic compounds on a HP Innowax column; MS, identified on the basis of computer matching of the mass spectra with those of the Wiley and MassFinder libraries

\subsection{Extraction of Essential oil}

Plant material was subjected to hydrodistillation in a Clevenger apparatus for $3 \mathrm{~h}$ to give an essential oil with a yield of $0.08 \%$. The essential oil was dried over anhydrous $\mathrm{Na}_{2} \mathrm{SO}_{4}$ and stored at $4^{\circ} \mathrm{C}$ till use.

\subsection{Analysis of the essential oil}

4.3.1. Gas Chromatography-FID (GC-FID) and Gas Chromatography-Mass Spectrometry (GC-MS):

The GC analysis was carried out using an Agilent 6890N GC system. FID detector temperature was $300^{\circ} \mathrm{C}$. To obtain the same elution order with GC-MS, simultaneous auto-injection was done on a duplicate of the same column applying the same operational conditions. Relative percentage amounts of the separated compounds were calculated from FID chromatograms.

The GC-MS analysis was carried out with an Agilent 5975 GC-MSD system. Innowax FSC column (60 m x $0.25 \mathrm{~mm}$, $0.25 \mathrm{~mm}$ film thickness) was used with helium as carrier gas $(0.8 \mathrm{~mL} / \mathrm{min})$. GC oven temperature was kept at $60^{\circ} \mathrm{C}$ for $10 \mathrm{~min}$ and programmed to $220^{\circ} \mathrm{C}$ at a rate of $4^{\circ} \mathrm{C} / \mathrm{min}$, and kept constant at $220^{\circ} \mathrm{C}$ for $10 \mathrm{~min}$ and then programmed to $240^{\circ} \mathrm{C}$ at a rate of $1^{\circ} \mathrm{C} / \mathrm{min}$. Split ratio was adjusted at $40: 1$. The injector temperature was set at $250^{\circ} \mathrm{C}$. Mass spectra were recorded at $70 \mathrm{eV}$. Mass range was from $\mathrm{m} / \mathrm{z} 35$ to 450 . The analysis results are expressed as mean \pm standard deviation $(n=3)$ as listed in Table 1.

\subsubsection{Identification of the compounds:}

Identification of the essential oil components were carried out by comparison of their relative retention times with those of authentic samples or by comparison of their relative retention index (RRI) to series of $n$-alkanes. Computer matching against commercial (Wiley GC/MS Library, MassFinder 3 Library) $[11,12]$ and in-house "Başer Library of Essential Oil Constituents" built up by genuine compounds and components of known oils, as well as MS literature data $[13,14]$ was used for the identification.

\subsection{Antimicrobial activity assays}

Escherichia coli NRRL B-3008, Staphylococcus aureus ATCC 6538, S. epidermidis ATCC 14990, Pseudomonas aeruginosa ATCC 10145, Helicobacter pylori ATCC 43504 and Candida albicans ATCC 90028 standard strains were obtained from the American Type Culture Collection (ATCC) and Northern Regional Research Laboratory (NRRL). All microorganisms were stored at $-85^{\circ} \mathrm{C}$ in $15 \%$ sterile glycerol. The strains were cultured on Mueller-Hinton agar (MHA, Merck, Germany) and Mueller Hinton Broth (MHB, Merck) for E. coli, S. aureus, $S$. epidermidis and $P$. aeruginosa. Colombia agar containing $5 \%$ defibrinated sheep blood and Brucella broth containing 10 
Table 2. Antimicrobial activity of $S$. trojana essential oil (MIC, $\mu \mathrm{g} / \mathrm{mL}$ )

\begin{tabular}{|c|c|c|c|c|c|c|}
\hline & $\begin{array}{l}\text { Escherichia coli } \\
\text { NRRL } \\
\text { B-3008 }\end{array}$ & $\begin{array}{l}\text { Staphylococcus } \\
\text { aureus ATCC } \\
6538\end{array}$ & $\begin{array}{l}\text { S. epidermidis } \\
\text { ATCC } \\
14990\end{array}$ & $\begin{array}{l}\text { Pseudomonas } \\
\text { aeruginosa ATCC } \\
10145\end{array}$ & $\begin{array}{l}\text { Helicobacter pylori } \\
\text { ATCC } 43504\end{array}$ & $\begin{array}{l}\text { C. albicans ATCC } \\
90028\end{array}$ \\
\hline Essential oil & $>1000$ & $>1000$ & $>1000$ & $>1000$ & 250 & $>1000$ \\
\hline Chloramphenicol & 8 & 8 & 4 & $>32$ & 16 & - \\
\hline Tetracycline & 16 & 0.25 & $>32$ & $>32$ & 0.025 & - \\
\hline Amphotericin B & - & - & - & - & - & 0.031 \\
\hline
\end{tabular}

$\%$ fetal bovine serum were used for H. pylori strain, whereas the Candida strain was refreshed on Potato Dextrose Agar (PDA, Merck) plates and RPMI medium at $37^{\circ} \mathrm{C}$. Thereafter, all microorganisms were standardized versus McFarland No: $0.5(1 \times 108 \mathrm{CFU} / \mathrm{mL}$ for bacteria and $1 \times 106 \mathrm{CFU} / \mathrm{mL}$ for Candida sp.) in sterile saline (\% 0.85), turbidimetrically $[15,16]$. Modified microdilution assay $[17,18]$ was used to determine the antimicrobial activity of sample. Stock solution of the test sample was prepared in dimethylsulfoxide (DMSO) and diluted with sterile distilled water. Essential oil dilution series were prepared from $1000 \mu \mathrm{g} / \mathrm{mL}$ to $2 \mu \mathrm{g} / \mathrm{mL}$ in 96 well microtiter plates. $100 \mu \mathrm{L}, 1: 100$ diluted bacterial suspensions [17] 1:10 diluted Helicobacter suspensions [19, 20] and 1:1000 diluted Candida suspensions [15] were then added to each well. After incubation at $37{ }^{\circ} \mathrm{C}$ for $18-24 \mathrm{~h}$, for staining of viable microorganisms, $20 \mu \mathrm{L} 0.01 \%$ resazurin solution was added to all of the plate. The first blue well was determined as the minimal inhibitory concentration (MIC, $\mu \mathrm{g} / \mathrm{mL}$ ). The last row containing medium with microorganism was used as negative control and medium served as a positive growth control. Chloramphenicol, tetracycline and amphotericin B (Sigma, Germany) were used as standard antimicrobial agents at concentration range $0.016-32 \mu \mathrm{g} / \mathrm{mL}$. All experiments were repeated in triplicate and average MICs are given in Table 2.

\section{Authorship statement}

Author contributions: Concept - H.K., B.D.; Design H.K., F.D.; Supervision - B.D., F.D.; Resource - H.K., B.D.; Materials - H.K., B.D.; Data Collection and/or Processing N.K., B.D.; Analysis and/or Interpretation - B.D, N.K, F.D., H.K.; Literature Search - H.K., B.D.; Writing - H.K., N.K., B.D., F.D.; Critical Reviews - H.K, B.D., F.D.

\section{Conflict of interest statement}

The authors declared no conflict of interest.

\section{References}

1. Gonzalez-Burgos E, Carretero ME, Gomez-Serranillos MP. Sideritis spp.: Uses, chemical composition and pharmacological activities-A review. J Ethnopharmacol 2011; 135: 209-25.

2. Bulut G, Tuzlacı E. An ethnobotanical study of medicinal plants in Bayramiç (Çanakkale-Turkey). Marmara Pharm J 2015; 19: 268-82.

3. Huber-Morath A. Sideritis L. In: Davis PH. (Ed). Flora of Turkey and East Aegean Islands, Vol 7. University Press, Edinburgh. 1982, pp. 178-199.

4. Kıllı̧ Ö. Essential oil composition of two Sideritis L. taxa from Turkey: A chemotaxonomic approach. Asian J Chem 2014; 26 : 2466-70.

5. Topçu G, Gören AC, Kılıç T, Ylldız YK, Tümen G. Diterpenes from Sideritis trojana. Nat Prod Lett 2002; 16: 33-7.

6. Kırımer N, Demirci B, İşcan G, Başer KHC, Duman H. Composition of the essential oils of two Sideritis species from Turkey and antimicrobial activity. Chem Nat Comp 2008; 44:121-3.

7. Kırmızıbekmez H, Arıburnu E, Masullo M, Festa M, Capasso A, Yeşilada E, Piacente S, Iridoid, phenylethanoid and flavonoid glycosides from Sideritis trojana. Fitoterapia 2012; 83: 130-6.

8. Kılıç T, Yıldız YK, Gören AC, Tümen G, Topçu G. Phytochemical analysis of some Sideritis species of Turkey. Chem Nat Comp 2003; 39: 453-6.

9. Kırımer N, Başer KHC, Demirci B, Duman H. Essential oils of the Sideritis species of Turkey belonging to the section Empedoclia. Chem Nat Comp 2004; 40: 19-23.

10. Başer KHC. Aromatic biodiversity among the flowering plant taxa of Turkey. Pure Appl Chem 2002; 74: 527-45.

11. McLafferty FW, Stauffer DB. The Wiley/NBS Registry of Mass Spectral Data. J Wiley and Sons, New York, USA. 1989.

12. Koenig WA, Joulain D, Hochmuth D H. Terpenoids and Related Constituents of Essential Oils. MassFinder 3, Hamburg, Germany. 2004.

13. Joulain D, Koenig WA. The Atlas of Spectra Data of Sesquiterpene Hydrocarbons. EB-Verlag, Hamburg, Germany. 1998.

14. ESO 2000. The Complete Database of Essential Oils. Boelens Aroma Chemical Information Service, The Netherlands. 1999.

15. CLSI. Clinical and Laboratory Standards Institute. Reference 
Method for Broth Dilution Antifungal Susceptibility Testing of Filamentous Fungi, Approved Standard-Second Edition Method 2002; M38-A2. 22: 1-27.

16. CLSI. Clinical and Laboratory Standards Institute. Methods for Dilution Antimicrobial Susceptibility Tests for Bacteria that grow aerobically, Approved Standard-Seventh Edition. 2006; 26: 1-4.

17. CLSI. Clinical and Laboratory Standards Institute. Performance Standards for Antimicrobial Susceptibility Testing; Seventeenth Informational Supplement, 2007;
M100-S17, 27 (1).

18. Demirci B, Toyota M, Demirci F, Dadandı MY, Başer KHC. Anticandidal pimaradiene diterpene from Phlomis essential oils. CR Chimie 2009; 12: 612-21.

19. EUCAST (2011). Clinical breakpoints for Helicobacter pylori, European Committee on Antimicrobial Susceptibility Testing.

20. Whitmire JM, Merrell DS. Successful culture techniques for Helicobacter species: General culture techniques for Helicobacter pylori. Methods Mol Biol 2012; 921: 17-27. 